\title{
Strategic Delegation in Price Competition
}

\author{
Werner Güth ${ }^{1}$, Kerstin Pull ${ }^{2}$, Manfred Stadler ${ }^{2}$ \\ ${ }^{1}$ Max Planck Institute of Economics, Strategic Interaction Group, Jena, Germany \\ ${ }^{2}$ Department of Business and Economics, University of Tübingen, Tübingen, Germany \\ Email: gueth@econ.mpg.de, kerstin.pull@uni-tuebingen.de, manfred.stadler@uni-tuebingen.de
}

Received July 6, 2012; revised August 1, 2012; accepted September 3, 2012

\begin{abstract}
We study price competition in heterogeneous markets where price decisions are delegated to agents. Principals implement a revenue sharing scheme to which agents react by commonly charging a sales price. The results of our model exemplify the importance of both intra- and interfirm interactions of principals and agents in competition. We show that price delegation can increase or decrease the firms' surplus depending on the heterogeneity of the market and the number of agents employed by the firms.
\end{abstract}

Keywords: Strategic Delegation; Agency Theory; Revenue Sharing

\section{Introduction}

Whereas principal-agent theory typically restricts itself to the analysis of intrafirm interaction by neglecting interfirm competition, most models in the theory of Industrial Organization (IO) focus purely on interfirm competition by assuming a unitary decision maker for each of the competing firms. While studying only one of these two interaction types certainly answers many questions, in some cases it may suggest questionable implications for real-world behavior facing typically both types of interaction. For instance, a standard principal-agent framework (see e.g. Grossman and Hart [1]) neglects interfirm competition and, hence, the influence of market conditions on intrafirm compensation schemes. Similarly, assuming a unitary decision maker in IO models of interfirm competition ignores the principal-agent relationships and thus the decisive reason why firms may abstain from profit maximization.

Of course, principals may be the only ones determining both, intrafirm and interfirm interactions. If principals, for instance, confront their agents with piece rates, all what agents have to do is match their efforts with the given piece rates, i.e., agents neither interact strategically with other agents of the same nor with those working in other firms. Thus if only principals are involved in intrafirm and interfirm interaction, the analysis is rather simple and straightforward. Here we focus, however, on situations where not only principals are "running the mill": in our model principals only determine the incentives for their agents who then choose their firm's sales policy. Hence, in this scenario, principals as well as agents are engaged in interfirm competition.
Our analysis is related to the strategic delegation analysis of Vickers [2], Fershtman [3], Fershtman and Judd [4], Sklivas [5], Caillaud, Jullien, and Picard [6] and Schmidt [7] who study intrafirm incentives for managers facing a market with interfirm quantity or price competition. In these delegation games, the profit-maximizing principals (the owners) implement an incentive scheme for their agents (the managers) based on a weighted difference of revenue and cost. Fumas [8] and Miller and Pazgal [9] consider an incentive scheme based on a weighted sum of a firm's own profit and its rival's profit. Kräkel [10] investigates tournament-like interfirm competition based on a principal-(one) agent framework. These models have in common that they restrict analysis to the delegation to manager agents who decide on prices or quantities but are not involved in production, i.e. they face no cost of producing. In contrast we are interested in the decisions of worker agents who will anticipate the consequences of their price or quantity decisions on their effort.

Güth, Pull and Stadler [11] have studied intrafirm and interfirm interaction between principals and agents in an integrative model. They analyzed how revenue sharing affects the behavior and payoffs on a homogeneous oligopoly market with quantity competition ${ }^{1}$. On most markets firms, however, compete in prices. Therefore, we explore the case where principals implement a revenue sharing scheme and agents compete via prices. The price decisions of all competing firms in the market determine the quantities to be produced by firms and,

${ }^{1}$ Quantity competition can be justified by the necessity of firms to set up capacities before engaging in price competition (see e.g. Kreps and Scheinkman [12]). 
hence, the effort costs of their agents.

The remainder of this paper is structured as follows: Section 2 describes a benchmark case with price competition between two monolithic firms. Section 3 introduces delegation and price competition by workers allowing for an integrative analysis of strategic intra- and interfirm interaction based on the realistic assumptions of price competition. Section 4 concludes.

\section{The Benchmark: Price Competition between Two Monolithic Firms}

We consider two competing firms $i=1,2$ in a heterogeneous market with firm specific sales amounting to

$$
q_{i}=\sum_{k} e_{i, k} ; i=1,2, k=1, \ldots, n,
$$

where $e_{i, k}$ denotes the effort level of agent $k$ employed in firm $i$. Sales are assumed to serve demand for differentiated products. To keep the model analytically tractable, we rely on linear demand functions of the standardized form

$$
q_{i}\left(p_{i}, p_{j}\right)=1-p_{i}+\theta\left(p_{j}-p_{i}\right) ; \quad i=1,2, i \neq j,
$$

for the two substitute goods with restrictions

$q_{i}>0, i=1,2$, where $1 / \theta \in(0, \infty)$ indicates the degree of market heterogeneity. In the limit case $\theta=0$ there are two coexisting monopoly markets without interfirm competition. In the other extreme case where $\theta \rightarrow \infty$ the market becomes homogeneous since, in the limit, any price difference will not leave (positive) demand for the more expensive seller. Costs of the agents' sales efforts are private and commonly known. All agents share the same quadratic effort-cost function

$$
c\left(e_{i, k}\right)=e_{i, k}^{2} / 2 \text {. }
$$

To provide a benchmark solution without intrafirm interaction let us first assume that both firms maximize their surplus for example by assuming a unitary decision maker for each firm who dictates effort levels and monetarily compensates his $n$ agents for their effort costs. Due to the strictly convex cost function, each firm $i$ will impose the same effort level $e_{i, k}=e_{i}$ for all workers $k=1, \cdots, n$. Thus the surplus for each firm can be expressed by

$$
\begin{aligned}
S_{i}\left(p_{i}, p_{j}\right) & =p_{i}\left(1-(1+\theta) p_{i}+\theta p_{j}\right) \\
& -\left(1-(1+\theta) p_{i}+\theta p_{j}\right)^{2} /(2 n) ; \quad i=1,2, i \neq j .
\end{aligned}
$$

From the first-order conditions the equilibrium prices are derived as

$$
p^{*}=\frac{1+\theta+n}{1+\theta+(2+\theta) n},
$$

leading to each firm's output

$$
q^{*}=\frac{(1+\theta) n}{1+\theta+(2+\theta) n}
$$

and surplus

$$
S^{*}=\frac{(1+\theta) n(1+\theta+2 n)}{2[1+\theta+(2+\theta) n]^{2}} .
$$

Some numerical results are summarized in Table 1 for a fixed number of $n=2$ agents per firm and in Table 2 for a fixed intermediate degree of heterogeneity, $\theta=1$. A decreasing degree of heterogeneity (an increasing $\theta$ ) lowers equilibrium prices and the firms' surplus even if agents' individual efforts and sales increase (see Table 1).

For a given degree of heterogeneity $(\theta=1)$ all outcome variables react monotonically to an increase of the same number $n$ of employees in both firms. Prices decline and agents' individual efforts converge to 0 whereas sales and surplus levels increase monotonically (see Table 2).

Rather than assuming that all members (principal and agents) of each firm are interested in maximizing the firm's surplus or that only one type of actor (the principal) essentially "runs the mill", we now include vertical and horizontal interaction by analyzing strategic delegation of price decisions.

\section{Strategic Delegation of Price Decisions}

For the integrative analysis of intrafirm and interfirm interaction, we assume that principals share revenues with their agents. Let $S_{i}$ denote the revenue share for all the agents of firm $i$ as a whole. Agents are assumed

Table 1. Numerical solution of the price-competition game with monolithic firms, $n=2$.

\begin{tabular}{ccccc}
\hline$\theta$ & 0 & 1 & $\ldots$ & $\theta \rightarrow \infty$ \\
\hline$p^{*}$ & 0.600 & 0.500 & $\ldots$ & 0.333 \\
$q^{*}$ & 0.400 & 0.500 & $\ldots$ & 0.666 \\
$e^{*}$ & 0.200 & 0.250 & $\ldots$ & 0.333 \\
$s^{*}$ & 0.200 & 0.188 & $\ldots$ & 0.111 \\
\hline
\end{tabular}

Table 2. Numerical solution of the price-competition game with monolithic firms, $\theta=1$.

\begin{tabular}{cccccccc}
\hline$n$ & 1 & 2 & 3 & $\ldots$ & 100 & $\ldots$ & $n \rightarrow \infty$ \\
\hline$p^{*}$ & 0.600 & 0.500 & 0.455 & $\ldots$ & 0.338 & $\ldots$ & 0.333 \\
$q^{*}$ & 0.400 & 0.500 & 0.555 & $\ldots$ & 0.662 & $\ldots$ & 0.667 \\
$e^{*}$ & 0.400 & 0.250 & 0.185 & $\ldots$ & 0.007 & $\ldots$ & 0.000 \\
$s^{*}$ & 0.160 & 0.188 & 0.198 & $\ldots$ & 0.221 & $\ldots$ & 0.222 \\
\hline
\end{tabular}


to be identical and to distribute their overall revenue share $s_{i} p_{i} q_{i}$ proportionally to each agent's individual contribution $e_{i, k} / q_{i}$. Agents can observe and control the efforts of the team members. This means that each individual agent in firm $i=1,2$ chooses the same effort $e_{i, k}=e_{i}$ for all workers $k=1, \cdots, n$ and realizes the net utility

$$
\begin{aligned}
U_{i}\left(s_{i}, p_{i}, p_{j}\right) & =s_{i} p_{i} e_{i}-e_{i}^{2} / 2 \\
= & s_{i} p_{i}\left(1-(1+\theta) p_{i}+\theta p_{j}\right) / n \\
& -\left(1-(1+\theta) p_{i}+\theta p_{j}\right)^{2} /\left(2 n^{2}\right),
\end{aligned}
$$

where $p_{i}$ is the price decision made by the agents of firm $i=1,2$, given the rival firm's price $p_{j}, i \neq j$. The analysis of this delegated price competition complements our former analysis of delegated quantity competition (Güth, Pull and Stadler [5]). Both scenarios have in common that agents anticipate the effects of their sales choice (price or quantity) and principals anticipate these decisions when implementing the revenue sharing scheme. Thus, from a technical point of view, the price- delegation game can be solved analogously to the quantity-delegation game. Indeed, in the standard principalagent scenario where $n=1$ and $\theta=0$ the results for our price-delegation game coincide with those of the quantity-delegation game (Güth, Pull and Stadler [11, p. 372]).

\subsection{The Delegation Game with a Variable Degree of Market Heterogeneity}

To study the influence of market heterogeneity on the compensation scheme, we first restrict our analysis to the case of $n=2$ agents in each firm and neglect fixed compensation payments which would leave the strategic decisions as well as the firms' surplus unchanged. Maximization of agent utility

$$
\begin{aligned}
U_{i}\left(s_{i}, p_{i}, p_{j}\right)= & s_{i} p_{i}\left(1-(1+\theta) p_{i}+\theta p_{j}\right) / 2 \\
& -\left(1-(1+\theta) p_{i}+\theta p_{j}\right)^{2} / 8
\end{aligned}
$$

with respect to the price $p_{i}$ yields the equilibrium prices choices

$$
p_{i}\left(s_{i}, s_{j}\right)=\frac{(1+2 \theta)(1+\theta)^{2}+2(1+\theta)(1+2 \theta) s_{i}+2(1+\theta)(2+3 \theta) s_{j}+4(2+3 \theta) s_{i} s_{j}}{(1+2 \theta)(1+\theta)^{2}+2(1+\theta)\left(2+4 \theta+\theta^{2}\right)\left(s_{i}+s_{j}\right)+4\left(4+8 \theta+3 \theta^{2}\right) s_{i} s_{j}}
$$

for $i=1,2, i \neq j$, as functions depending on the compensation schemes, i.e. on the strategic variables $\left(s_{i}, s_{j}\right)$

$$
q_{i}\left(s_{i}, s_{j}\right)=\frac{2(1+2 \theta)(1+\theta)^{2} s_{i}+4\left(2+5 \theta+3 \theta^{2}\right) s_{i} s_{j}}{(1+2 \theta)(1+\theta)^{2}+2(1+\theta)\left(2+4 \theta+\theta^{2}\right)\left(s_{i}+s_{j}\right)+4\left(4+8 \theta+3 \theta^{2}\right) s_{i} s_{j}},
$$

the individual effort levels $e_{i}=q_{i} / 2$, and the principals' profits

$$
\pi_{i}\left(s_{i}, s_{j}\right)=\left(1-s_{i}\right) p_{i} q_{i}=N / D, \quad i=1,2, i \neq j,
$$

where

$$
\begin{array}{r}
N=2\left(1-s_{i}\right)\left[(1+2 \theta)(1+\theta)^{2}+2(1+\theta)(1+2 \theta) s_{i}\right. \\
\left.+2(1+\theta)(2+3 \theta) s_{j}+4(2+3 \theta) s_{i} s_{j}\right] \\
\times\left[(1+2 \theta)(1+\theta)^{2} s_{i}+2\left(2+5 \theta+3 \theta^{2}\right) s_{i} s_{j}\right]
\end{array}
$$

and

$$
p^{* *}=\frac{(1+2 \theta)(1+\theta)^{2}+2(1+\theta)(3+5 \theta) s^{* *}+4(2+3 \theta) s^{* * 2}}{(1+2 \theta)(1+\theta)^{2}+4(1+\theta)\left(2+4 \theta+\theta^{2}\right) s^{* *}+4\left(4+8 \theta+3 \theta^{2}\right) s^{* * 2}},
$$

output levels

$$
q^{* *}=\frac{2(1+\theta)\left(1+3 \theta+2 \theta^{2}\right) s^{* *}+4\left(2+5 \theta+3 \theta^{2}\right) s^{* * 2}}{(1+2 \theta)(1+\theta)^{2}+4(1+\theta)\left(2+4 \theta+\theta^{2}\right) s^{* *}+4\left(4+8 \theta+3 \theta^{2}\right) s^{* * 2}}
$$

and effort levels

$$
e^{* *}=\frac{(1+\theta)\left(1+3 \theta+2 \theta^{2}\right) s^{* *}+2\left(2+5 \theta+3 \theta^{2}\right) s^{* * 2}}{(1+2 \theta)(1+\theta)^{2}+4(1+\theta)\left(2+4 \theta+\theta^{2}\right) s^{* *}+4\left(4+8 \theta+3 \theta^{2}\right) s^{* 2}}
$$


Finally, principals' profits are $\pi^{* *}=\left(1-s^{* *}\right) p^{* *} q^{* *}$.

Due to the nonlinearity of the reaction functions the game can in general be solved only by using numerical techniques. An exception is the case of monopoly, i.e. the market structure characterized by two independent markets due to $\theta=0^{2}$. In this case agents' price decisions (1) simplify to

$$
p_{i}\left(s_{i}\right)=\frac{1+2 s_{i}+4 s_{j}+8 s_{i} s_{j}}{1+4\left(s_{i}+s_{j}\right)+16 s_{i} s_{j}}=\frac{1+2 s_{i}}{1+4 s_{i}}
$$

and imply the output levels

$$
q_{i}\left(s_{i}\right)=\frac{2 s_{i}}{1+4 s_{i}} .
$$

Hence, the principals' profits are

$$
\pi\left(s_{i}\right)=\frac{2 s_{i}\left(1+s_{i}-2 s_{i}^{2}\right)}{\left(1+4 s_{i}\right)^{2}} .
$$

The symmetric first-order conditions from maximizing the profits with respect to $S_{i}$ lead to the cubic equation

$$
8 s_{i}^{3}+6 s_{i}^{2}+2 s_{i}-1=0,
$$

which has the unique real solution

$s^{* *}(\theta=0 ; n=2)=1 / 4$. Given this revenue-sharing rule the agents charge the prices $p^{* *}=3 / 4$ implying output levels $q^{* *}=1 / 4$ and effort levels $e^{* *}=1 / 8$ such that the principals realize the profits $\pi^{* *}=9 / 64$, agents the utility $U^{* *}=1 / 64$, and the firm as a whole the surplus $S^{* *}=11 / 64$.

Numerical solutions $\left(s^{* *}, p^{* *}, q^{* *}, e^{* *}, \pi^{* *}, U^{* *}, S^{* *}\right)$ for a varying degree of heterogeneity are presented in Table 3. As can be seen, a decreasing degree of heterogeneity induces principals to offer higher revenue shares to their agents. Higher revenue shares imply higher sales efforts by the agents corresponding to lower prices. In the case of two separate markets $(\theta=0)$ agents charge the highest prices. Starting from that benchmark case declining prices result from declining heterogeneity

Table 3. Numerical solution of the price-delegation game, $n=$ 2.

\begin{tabular}{ccccc}
\hline$\theta$ & 0 & 1 & $\ldots$ & $\theta \rightarrow \infty$ \\
$s^{* *}$ & 0.250 & 0.298 & $\ldots$ & 0.366 \\
$p^{* *}$ & 0.750 & 0.685 & $\ldots$ & 0.577 \\
$q^{* *}$ & 0.250 & 0.315 & $\ldots$ & 0.423 \\
$e^{* *}$ & 0.125 & 0.157 & $\ldots$ & 0.211 \\
$\pi^{* *}$ & 0.141 & 0.151 & $\ldots$ & 0.155 \\
$U^{* *}$ & 0.016 & 0.020 & $\ldots$ & 0.022 \\
$S^{* *}$ & 0.172 & 0.190 & $\ldots$ & 0.200 \\
\hline
\end{tabular}

(larger $\theta$ ) thereby increasing the revenues to be shared between principals and agents. The revenue effect dominates leading to (slightly) higher profits as a result of a lower market heterogeneity. Agents' utility and, hence, the firms' surplus also increase.

Compared to the benchmark solution (Table 1) of Section 2, which neglects intrafirm conflicts, delegation leads to higher prices and lower efforts of agents throughout. The surplus in the delegation game is higher if markets are homogeneous but is lower in case of very heterogeneous markets. This interesting result suggests that it depends on the basic conditions of the market under consideration whether a firm as a whole gains from delegation.

\subsection{The Delegation Game with a Variable Number of Agents}

To study how the number of agents hired by both principals affects the market outcome, we set the parameter $\theta$ equal to an intermediate degree of heterogeneity, $\theta=1$, and vary the number $n$ of agents symmetrically across firms ${ }^{3}$. Maximization of agent utility

$U_{i}\left(s_{i}, p_{i}, p_{j}\right)=s_{i} p_{i}\left(1-2 p_{i}+p_{j}\right) / n-\left(1-2 p_{i}+p_{j}\right)^{2} /\left(2 n^{2}\right)$

with respect to the prices $p_{i}$ leads to the equilibrium price choices

$$
p_{i}\left(s_{i}, s_{j}\right)=\frac{12+6 n s_{i}+10 n s_{j}+5 n^{2} s_{i} s_{j}}{12+14 n s_{i}+14 n s_{j}+15 n^{2} s_{i} s_{j}}
$$

for $i=1,2, i \neq j$ as functions of the strategic variables $\left(s_{i}, s_{j}\right)$, chosen by the two principals. The resulting profits are

$$
\begin{aligned}
& \pi_{i}\left(s_{1}, s_{2}\right)=\left(1-s_{i}\right) p_{i}\left(1-2 p_{i}+p_{j}\right)=N / D, \\
& i=1,2, i \neq j,
\end{aligned}
$$

where

$$
\begin{aligned}
N= & 2 n\left(72 s_{i}+36 n s_{i}^{2}+120 n s_{i} s_{j}\right. \\
& +60 n^{2} s_{i}^{2} s_{j}+50 n^{2} s_{i} s_{j}^{2}+25 n^{3} s_{i}^{2} s_{j}^{2} \\
& -72 s_{i}^{2}-36 n s_{i}^{3}-120 n s_{i}^{2} s_{j}-60 n^{2} s_{i}^{3} s_{j} \\
& \left.-50 n^{2} s_{i}^{2} s_{j}^{2}-25 n^{3} s_{i}^{3} s_{j}^{2}\right)
\end{aligned}
$$

and

$$
D=\left(12+14 n s_{i}+14 n s_{j}+15 n^{2} s_{i} s_{j}\right)^{2} .
$$

The first-order conditions for maximizing $\pi_{i}\left(s_{i}, s_{j}\right)$

\footnotetext{
${ }^{2}$ Note, however, that unlike in Section 2 it maintains intrafirm interaction and thus non-monolithic firms.

${ }^{3}$ Endogenizing the number of agents in both firms would require to study cases with different numbers of agents in the two firms. For such a case, analytic results are very difficult to obtain. We thus restrict ourselves to studying how a symmetric change in the number of agents employed by each firm influences results via comparative statics.
} 
with respect to $s_{i}, i=1,2$, and the obvious symmetry of the solution again lead to a sixth-order polynomial equation for each number $n$ of a agents hired by both principals with the solution $s^{* *}=s^{* *}(n ; \theta=1) \in(0,1)$. Equilibrium prices are

$$
p^{* *}=\frac{12+16 n s^{* *}+5 n^{2} s^{* * 2}}{12+28 n s^{* *}+15 n^{2} s^{* * 2}},
$$

output levels

$$
q^{* *}=\frac{12 n s^{* *}+10 n^{2} s^{* * 2}}{12+28 n s^{* *}+15 n^{2} s^{* * 2}},
$$

and effort levels

$$
e^{* *}=\frac{12 s^{* *}+10 n s^{* * 2}}{12+28 n s^{* *}+15 n^{2} s^{* * 2}} .
$$

Table 4 illustrates how the solution $\left(s^{* *}, p^{* *}, q^{* *}, e^{* *}, \pi^{* *}, U^{* *}, s^{* *}\right)$ depends on the number $n$ of agents employed by each seller firm. As can be seen, an increasing number of agents inquires principals to offer lower revenue shares to their agents. Declining marginal effort costs of agents imply higher quantities and lower prices. The principals' profits first increase and later on decrease with more and more agents. A similar inverted-U shaped relationship holds for the firms' surplus whereas agents' utility is monotonically decreasing.

A comparison of the results to those of the benchmark case (Table 2) in Section 2 shows that price delegation results in higher prices and lower effort levels. The surplus in the delegation game is lower in case of a small number of agents but higher in case of a large number of agents. Of course, in the limit case $n \rightarrow \infty$ effort costs go to zero and the solutions coincide. Therefore it depends on intrafirm organization (treated as exogenous in our analysis) whether the firm as a whole gains from delegation or not.

\section{Summary and Conclusion}

Price delegation to sales managers is usual. But managers

Table 4. Numerical solution of the price-delegation game, $\theta=1$.

\begin{tabular}{cccccccc}
\hline$n$ & 1 & 2 & 3 & $\ldots$ & 100 & $\ldots$ & $n \rightarrow \infty$ \\
$s^{* *}$ & 0.363 & 0.298 & 0.259 & $\ldots$ & 0.040 & $\ldots$ & 0.000 \\
$p^{* *}$ & 0.765 & 0.685 & 0.641 & $\ldots$ & 0.429 & $\ldots$ & 0.333 \\
$q^{* *}$ & 0.235 & 0.315 & 0.359 & $\ldots$ & 0.571 & $\ldots$ & 0.667 \\
$e^{* *}$ & 0.235 & 0.157 & 0.120 & $\ldots$ & 0.006 & $\ldots$ & 0.000 \\
$\pi^{* *}$ & 0.115 & 0.151 & 0.171 & $\ldots$ & 0.235 & $\ldots$ & 0.222 \\
$U^{* *}$ & 0.038 & 0.020 & 0.013 & $\ldots$ & 0.000 & $\ldots$ & 0.000 \\
$S^{* *}$ & 0.153 & 0.190 & 0.209 & $\ldots$ & 0.235 & $\ldots$ & 0.222 \\
\hline
\end{tabular}

do not suffer from the effort of producing what they sell. In our analysis this effect is taken into account by assuming that the agents who set the sales prices are the same who suffer from exerting effort. Our price-delegation model assumes that both, principals and agents, compete with each other. Principals implement a revenue sharing scheme to which agents react by choosing a sales price and by producing what is demanded. We thus complement our former investigation of homogeneous markets with quantity competition by an analysis of more or less heterogeneous markets with price competition. Both types of delegation can be observed in markets for specific goods or services.

Our study demonstrates how implementing revenue sharing affects intra- and interfirm interaction between principals (the owners) and agents (the workers) who suffer the cost of producing more. Thus low effort cost in case of low output provides an incentive for choosing high prices, an effect which is absent when sales manager neglect producing efforts. Therefore, more intensive competition due to a decreasing market heterogeneity or due to an increasing number of agents, hired by both firms, leads to lower prices and higher revenues. Accordingly we derive an inverted U-shaped relationship between the degree of market heterogeneity and the number of agents on the one hand and the firms' surplus on the other. Whether price delegation increases or decreases the surplus compared to the benchmark case of monolithic firms depends decisively on the intrafirm organization and the interfirm (market) structure.

The derived results pose quite a challenge for our intuition of how complex markets operate. In our view, this alone justifies the attempt to complement our former analysis of homogeneous markets with quantity competition by one of more or less heterogeneous markets with price competition. Both studies together will hopefully help to understand more thoroughly what has to be expected from an integrative analysis of intrafirm delegation and interfirm sales competition.

\section{REFERENCES}

[1] S. J. Grossman and O. D. Hart, "An Analysis of the Principal-Agent Problem," Econometrica, Vol. 51, No. 1, 1983, pp. 7-45. doi:10.2307/1912246

[2] J. Vickers, "Delegation and the Theory of the Firm," Economic Journal, Vol. 95, 1985, pp. 138-147. doi: $10.2307 / 2232877$

[3] C. Fershtman, "Managerial Incentives as a Strategic Variable in Duopolistic Environment," International Journal of Industrial Organization, Vol. 3, No. 2, 1985, pp. 245253. doi:10.1016/0167-7187(85)90007-4

[4] C. Fershtman and K. L. Judd, "Equilibrium Incentives in Oligopoly," American Economic Review, Vol. 77, No. 5, 1987, pp. 927-940. 
[5] S. D. Sklivas, "The Strategic Choice of Managerial Incentives," Rand Journal of Economics, Vol. 18, No. 3, 1987, pp. 452-458. doi:10.2307/2555609

[6] B. Caillaud, B. Jullien and P. Picard, "Competing Vertical Structures: Precommitment and Renegotiation," Econometrica, Vol. 63, No. 3, 1995, pp. 621-646. doi: $10.2307 / 2171910$

[7] K. M. Schmidt, "Managerial Incentives and Product Market Competition," Review of Economic Studies, Vol. 64, No. 2, 1997, pp. 191-213. doi:10.2307/2971709

[8] V. S. Fumas, "Relative Performance Evaluation of Management: The Effects of Industrial Competition and Risk Sharing," International Journal of Industrial Organization, Vol. 10, No. 3, 1992, pp. 473-489. doi:10.1016/0167-7187(92)90008-M
[9] N. H. Miller and A. I. Pazgal, "The Equivalence of Price and Quantity Competition with Delegation," Rand Journal of Economics, Vol. 32, No. 2, 2001, pp. 284-301. doi: $10.2307 / 2696410$

[10] M. Kräkel, "Strategic Delegation in Oligopolistic Tournaments," Review of Economic Design, Vol. 9, No. 4, 2005, pp. 377-396. doi:10.1007/s10058-005-0136-8

[11] W. Güth, K. Pull and M. Stadler, "Intrafirm Conflicts and Interfirm Competition," Homo Oeconomicus, Vol. 28, No. 3, 2011, pp. 367-378.

[12] D. Kreps and J. Scheinkman, "Quantity Precommitment and Bertrand Competition Yield Cournot Outcomes," Bell Journal of Economics, Vol. 14, No. 2, 1983, pp. 326-337. doi: $10.2307 / 3003636$ 